\section{Evidence of action in breast cancer}

Mutations in p53, overexpression of c-erbB-2, and high tumour proliferation are all associated with age under 40 years and with adverse prognosis in breast cancer. ${ }^{1}$ When p53 status and tumour proliferation markers are included in multivariate analyses, age no longer remains an independent prognostic factor. ${ }^{2}$ This suggests that these factors contribute significantly to the adverse prognostic effect of young age. But what evidence is there that these molecular phenotypes also modify response to treatment? The presence of mutated p53 is, as expected, associated with reduced benefit from adjuvant systemic treatment. ${ }^{3}$ High tumour proliferation is at best of no predictive value or is indicative of worse response in locally advanced disease. ${ }^{4}$ Similarly, overexpression of c-erbB-2 is associated with the development of resistance to tamoxifen and possibly reduced benefit from adjuvant systemic treatment. ${ }^{5}$ Thus none of these three factors can be held responsible for both adverse prognosis and improved treatment outcome.

Other possible candidates to explain the phenomenon are the two breast cancer predisposition genes BRCA1 and 2. These proteins have a role in the repair of spontaneous DNA damage and that induced by radiotherapy and some chemotherapy drugs. Mutations in these genes may thus make tumour cells more responsive to treatment. However, since only $5.9 \%$ of women with breast cancer aged younger than 36 have germline mutation in these genes ${ }^{6}$ and somatic mutations are not found in sporadic breast cancer, it is unlikely that Kroman et al's results can be explained by mutations in BRCA1 or 2. In addition, it remains to be shown whether BRCA1 or 2 mutant breast cancers are more responsive to radiotherapy or chemotherapy. Importantly, there is no evidence that mutation carriers have a worse prognosis than stage and grade matched controls. ${ }^{7}$

\section{Future research}

The biological explanations for Kroman et al's observations remain unclear. We require more information about the molecular pathology correlated with the effects of treatment on survival in large clinical trials. The development of cDNA microarray technology will soon allow us to analyse the differences in expression of thousands of genes in breast tumour specimens. This may show patterns of gene expression associated with early onset breast cancer and subsequent correlations with prognosis and outcome after treatment. It will then be critical to observe whether age remains an independent significant prognostic factor in women with small, low grade, node negative tumours, currently defined as low risk. Until this information is available, based on the results of this study, oncologists may rightly consider young age alone an indicator of poorer prognosis and a relative indication for adjuvant chemotherapy.

Competing interests: None declared.

1 Bertheau P, Steinberg SM, Merino MJ. C-erbB-2, p53, and nm23 gene product expression in breast cancer in young women: immunohistochemical analysis and clinicopathologic correlation. Hum Pathol 1998;29:323-9.

2 Albain KS, Allred DC, Clark GM. Breast cancer outcome and predictors of outcome: are there age differentials? J Natl Cancer Inst Monogr 1994;(16):35-42.

3 Bergh J, Norberg T, Sjögren S, Lindgren A, Holmberg L. Complete sequencing of the p53 gene provides prognostic information in breast cancer patients, particularly in relation to adjuvant systemic therapy and cancer patients, particularly in relation to
radiotherapy. Nature Med 1995;1:1029-34.

4 Daidone MG, Veneroni S, Benini E, Tomasic G, Coradini D, Mastore M, et al. Biological markers as indicators of response to primary and adjuvant chemotherapy in breast cancer. Int J Cancer 1999;84:580-6.

5 Gusterson BA, Gelber RD, Goldhirsch A, Price KN, Save-Soderborgh J, Anbazhagan R, et al. Prognostic importance of c-erbB-2 expression in breast cancer. International (Ludwig) Breast Cancer Study Group. J Clin Oncol 1992;10:1049-56.

6 Peto J, Collins N, Barfoot R, Seal S, Warren W, Rahman N, et al. Prevalence of BRCA1 and BRCA2 gene mutations in patients with earlyonset breast cancer J Natl Cancer Inst 1999;91:943-9.

7 Phillips KA, Andrulis IL, Goodwin PJ. Breast carcinomas arising in carriers of mutations in BRCA1 or BRCA2: are they prognostically different? J Clin Oncol 1999;17:3653-63.

\title{
Obstructive sleep apnoea syndrome as a risk factor for hypertension: population study
}

Peretz Lavie, Paula Herer, Victor Hoffstein

\author{
Abstract \\ Objective To assess whether sleep apnoea syndrome \\ is an independent risk factor for hypertension. \\ Design Population study. \\ Setting Sleep clinic in Toronto. \\ Participants 2677 adults, aged 20-85 years, referred \\ to the sleep clinic with suspected sleep apnoea \\ syndrome. \\ Outcome measures Medical history, demographic \\ data, morning and evening blood pressure, and whole \\ night polysomnography. \\ Results Blood pressure and number of patients with \\ hypertension increased linearly with severity of sleep \\ apnoea, as shown by the apnoea-hypopnoea index. \\ Multiple regression analysis of blood pressure levels
}

of all patients not taking antihypertensives showed that apnoea was a significant predictor of both systolic and diastolic blood pressure after adjustment for age, body mass index, and sex. Multiple logistic regression showed that each additional apnoeic event per hour of sleep increased the odds of hypertension by about $1 \%$, whereas each $10 \%$ decrease in nocturnal oxygen saturation increased the odds by $13 \%$.

Conclusion Sleep apnoea syndrome is profoundly associated with hypertension independent of all relevant risk factors.

Sleep Laboratory, Bruce Rappaport Faculty of Medicine, Israel Institute of Technology, Haifa, Israel

Peretz Lavie professor Paula Herer statistician

continued over

BMJ 2000;320:479-82

\section{Introduction}

The strong association between obstructive sleep apnoea syndrome and hypertension has attracted con- 
Division of

Respiratory

Medicine,

St Michael's

Hospital, University

of Toronto, Ontario,

Canada

Victor Hoffstein

professor of medicine

Correspondence to: P Lavie

plavie@techunix.

technion.ac.il siderable attention in recent years. ${ }^{1-6}$ Despite the accumulated evidence suggesting a causal relation between these two conditions, doubts have been raised about how much of this association is contributed by confounding variables, most notably obesity, age, and male sex. This argument diminished the importance of the syndrome as a major public health problem. ${ }^{7}$ Differentiating the contribution of confounding factors from that of the repeated apnoeic events and hypoxaemia requires large populations. In an unselected population of state employees, sleep related breathing disorders were a risk factor for hypertension, which was independent of age, body mass index, and sex. ${ }^{6}$ However, because the population was a sample of the general population rather than of patients with suspected sleep disorders, less than $4 \%$ of that population had moderate or severe sleep apnoea. ${ }^{6}$

No large scale investigations have examined the relation between blood pressure, severity of apnoea, and various confounding factors in patients attending sleep clinics. These patients generally present with more severe forms of sleep related breathing disorders and more confounding variables than the general population, and therefore may be expected to show a different relation between apnoeic events and blood pressure. We investigated these relations in a large population of patients with sleep disorders attending a clinic

\section{Methods}

Participants

We examined prospectively 2677 adults (aged 20-85 years) referred to the St Michael's Hospital sleep clinic with suspected sleep apnoea. All were both nonselected and consecutively referred for diagnostic sleep recordings over a 10 year period.

\section{Protocol}

Nocturnal polysomnography was performed in hospital. This included monitoring of both respiration, with inductance plethysmography and oronasal temperature as substitute measurements of respiratory effort and flow, and oxygen saturation. From these measures we obtained the apnoea-hypopnoea index (total number of apnoeic events plus hypopnoeic events divided by hours of sleep) and the lowest and mean nocturnal oxygen saturation; we also recorded the percentage of time spent asleep with oxygen saturation below 90\%. Apnoea was defined as a cessation in airflow of at least 10 seconds, and hypopnoea was defined as a decrease in the amplitude of the respiratory signal of at least $50 \%$ for a minimum of 10 seconds followed by either a decrease in oxygen saturation of $4 \%$ or signs of physiological arousal.

Anthropometric measurements-We measured the patients' height and weight and neck, hip, and waist circumference, and we calculated their body mass index and waist to hip ratio.

Smoking status was defined as never, present, or past smoker, and pack years of smoking.

Blood pressure measurements were taken six times under standard conditions, with the patients awake and supine, either just before turning off the lights (evening measurements) or just before getting out of bed (morning measurements). Our analysis deals only with mean morning blood pressure readings. Repeating the analysis with the evening values provided similar results.
Table 1 Anthropometric, sleep, and blood pressure data in 2677 adults attending sleep clinic

\begin{tabular}{lccc} 
Variable & No & Mean (SD) & Range \\
\hline Age (years) & 2677 & $48.6(12.6)$ & $20-85$ \\
\hline Height $(\mathrm{cm})$ & 2674 & $170.5(9.4)$ & $122-200$ \\
\hline Weight $(\mathrm{kg})$ & 2674 & $88.8(21.2)$ & $43-211$ \\
\hline Body mass index $\left(\mathrm{kg} / \mathrm{m}^{2}\right)$ & 2674 & $30.5(6.8)$ & $15.9-68.9$ \\
\hline Neck circumference $(\mathrm{cm})$ & 2645 & $40.4(4.5)$ & $29-59$ \\
\hline Hip circumference $(\mathrm{cm})$ & 1921 & $108.0(13.8)$ & $74-180$ \\
\hline Waist circumference $(\mathrm{cm})$ & 1920 & $103.3(17.0)$ & $41-186$ \\
\hline Waist:hip ratio & 1917 & $0.95(0.08)$ & $0.53-1.24$ \\
\hline Pack years of smoking & 2607 & $12.5(18.4)$ & $0-150$ \\
\hline Apnoea-hypopnoea index & 2675 & $21.8(24.9)$ & $0-152.6$ \\
\hline Nadir nocturnal oxygen saturation $(\%)$ & 2674 & $80.1(12.9)$ & $10-96.8$ \\
\hline Mean nocturnal oxygen saturation $(\%)$ & 2673 & $92.0(3.5)$ & $54-99$ \\
\hline Morning systolic blood pressure $(\mathrm{mm} \mathrm{Hg})$ & 2677 & $123.3(18.6)$ & $75-220$ \\
\hline Morning diastolic blood pressure $(\mathrm{mm} \mathrm{Hg})$ & 2677 & $73.0(11.1)$ & $28-122$ \\
\hline
\end{tabular}

\section{Hypertension}

Hypertension was defined as taking antihypertensives without regard to the actual measurement of blood pressure, or having a systolic blood pressure reading greater than $140 \mathrm{~mm} \mathrm{Hg}$ or a diastolic blood pressure reading greater than $90 \mathrm{~mm} \mathrm{Hg}$. The same definition was used in a study of hypertension in sleep apnoea based on a random sample of the population. ${ }^{6}$

Statistical analysis

We analysed the association between sleep apnoea and blood pressure with univariate analysis, without any adjustment for confounding variables. Linear trends were verified using the Cochran-Armitage trend test ${ }^{8}$ for linearity for categorical data, and regression lines for parametric data. We used multiple linear regression to identify the variables that made an important contribution to the variability of blood pressure and to adjust for confounding variables with analysis of covariance. Finally, we used multiple logistic regression modelling to determine the odds ratios of having hypertension associated with an increase in the apnoea-hypopnoea index and a decrease in oxygen saturation. Statistical analysis was performed using SAS software.

\section{Results}

Univariate analysis

Table 1 summarises the characteristics of the patient population of 1949 men and 728 women. Our patients were obese, middle aged males with mild to moderate sleep apnoea, and there was wide scatter in all variables.

To show how blood pressure levels vary with apnoea we divided our population into four groups: nonapnoeic controls (apnoea-hypopnoea index 10 or less), mild apnoea (greater than 10 and less than 31), moderate apnoea (greater than 30 and less than 51), and severe apnoea (greater than 50). Table 2 shows that unadjusted systolic and diastolic blood pressures increased with the apnoea-hypopnoea index. Trend analysis, however, showed that the important confounding factors, such as percentage of males, age, obesity (as reflected by body mass index, neck circumference, and waist to hip ratio), and smoking history also significantly increased with the apnoea-hypopnoea index (all $\mathrm{P}<0.0001$ ).

We used the Cochran-Armitage trend test ${ }^{8}$ to test for linearity in percentage of males, hypertension, and antihypertensive use. 
Multiple regression analysis-We performed multiple linear regression in 1865 patients not taking antihypertensives (table 3). This showed that the apnoeahypopnoea index was significantly related to diastolic and systolic blood pressure after adjustment for age and sex. Age and sex were significant covariates, but there was no interaction between the apnoea-hypopnoea index and age or sex. Smoking was only borderline statistically significant for the diastolic blood pressure, and therefore it was not included in further analysis. Stepwise linear regression, with the apnoea-hypopnoea index, age, and sex forced in the model, indicated that neck circumference (over body mass index, waist or hip circumference, and waist to hip ratio) was the most influential body habitus variable. When neck circumference was added to age and sex, the apnoea-hypopnoea index was still significantly related to diastolic and systolic blood pressures (adjusted $\mathrm{R}^{2} \quad 21.9 \%$ and $19.6 \%$ respectively). No interaction occurred between neck circumference and the apnoea-hypopnoea index. Under the conditions of the model, the $\beta$ coefficient for the apnoea-hypopnoea index indicates an increase of 0.10 and $0.04 \mathrm{~mm} \mathrm{Hg}$ in systolic and diastolic blood pressures respectively for each additional apnoeic event per hour of sleep. The model predicts, for example, that the mean (SD) morning blood pressure readings will be 6 (1.2) $\mathrm{mm} \mathrm{Hg}$ (systolic) and 4.7 (1.0) $\mathrm{mm} \mathrm{Hg}$ (diastolic) higher for severe sleep related breathing disorders (apnoea-hypopnoea index 60) versus no sleep related breathing disorders. The same results were found when the analysis was repeated with the lowest nocturnal oxygen saturation.

Multiple logistic regression-To evaluate the effect of the apnoea-hypopnoea index, we performed a multiple logistic regression model of sleep related breathing disorders and hypertension with terms for the apnoea-hypopnoea index, sex, age, body mass index, and an interaction for body mass index and apnoea-hypopnoea index. This indicated that an increase in 10 apnoeic events per hour of sleep increased the risk of having hypertension by about $11.0 \%$ ( $\beta$ coefficient 0.011 , table 4 and fig 1 ). A similar analysis replacing the apnoea-hypopnoea index with oxygen saturation nadir showed that each $10 \%$ decrease in saturation nadir increased the risk of having hypertension by about $13 \%(0.013$; table 5 and fig 2). Using percentage of time spent asleep below $90 \%$ oxygen saturation instead of nadir did not improve upon these results.

\section{Discussion}

We investigated the relation between the severity of sleep apnoea syndrome and hypertension in 2677 people attending a sleep clinic. Overall, $40 \%$ of our population were defined as hypertensive based on either medical history or blood pressure measurements taken immediately after sleep. Our results showed that sleep apnoea significantly contributed to hypertension independent of all relevant confounding variables. Each apnoeic event per hour of sleep added about $1 \%$ to the risk of having hypertension. To prove that sleep apnoea has an independent effect on blood pressure we used techniques for adjustment of case mix based on multivariate statistical models to account for several variables that are strong confounders. Since
Table 2 Changes in blood pressure and other confounding factors with severity of apnoea. Values are mean (SD) unless stated otherwise

\begin{tabular}{lcccc} 
& \multicolumn{4}{c}{ Severity of apnoea* } \\
\cline { 2 - 5 } Variable & $\begin{array}{c}\text { Controls } \\
(\mathbf{n = 1 2 4 9 )}\end{array}$ & $\begin{array}{c}\text { Mild apnoea } \\
(\mathbf{n}=\mathbf{7 5 5})\end{array}$ & $\begin{array}{c}\text { Moderate } \\
\text { apnoea } \\
(\mathbf{n}=\mathbf{3 0 8})\end{array}$ & $\begin{array}{c}\text { Severe } \\
\text { apnoea } \\
(\mathbf{n}=363)\end{array}$ \\
\hline Age (years) & $45.9(12.7)$ & $50.6(12.0)$ & $51.9(11.9)$ & $50.8(12.2)$ \\
\hline$\%$ Males & 61.5 & 78.0 & 86.4 & 89.3 \\
\hline Body mass index & $28.5(5.9)$ & $30.6(6.3)$ & $32.9(6.9)$ & $35.4(7.7)$ \\
\hline Neck circumference & $38.5(4.1)$ & $40.7(3.7)$ & $42.5(3.9)$ & $44.5(4.2)$ \\
\hline Waist:hip ratio & $0.92(0.09)$ & $0.96(0.07)$ & $0.99(0.06)$ & $1.01(0.06)$ \\
\hline Pack years of smoking & $10.9(17.7)$ & $13.4(18.7)$ & $14.4(19.2)$ & $14.6(18.9)$ \\
\hline Lowest oxygen saturation & $86.2(5.9)$ & $80.2(9.4)$ & $74.8(11.2)$ & $62.7(18.8)$ \\
\hline Mean oxygen saturation & $93.2(2.0)$ & $92.2(2.8)$ & $91.2(2.9)$ & $88.0(5.7)$ \\
\hline$\%$ Time spent below 90\% saturation & $6.2(14.8)$ & $14.5(22.2)$ & $26.4(25.8)$ & $45.3(28.6)$ \\
\hline$\%$ Hypertensive & 22.8 & 36.5 & 46.0 & 53.6 \\
\hline \% Antihypertensive drug use & 13.8 & 23.0 & 30.1 & 29.2 \\
\hline Morning systolic blood pressure & $118.1(16.9)$ & $124.8(18.4)$ & $128.5(18.7)$ & $133.4(18.7)$ \\
\hline Morning diastolic blood pressure & $70.1(10.4)$ & $73.6(10.6)$ & $76.1(10.7)$ & $78.8(11.5)$ \\
\hline
\end{tabular}

${ }^{*}$ Controls, non-apnoeic patients (apnoea-hypopnoea index $\leqslant 10$ ); mild apnoea $(>10$ and $<31$ ), moderate apnoea ( $>30$ and $<51)$, and severe apnoea $(>50)$.

Table 3 Multiple linear regression models for blood pressure measurements only in patients not taking antihypertensive drugs $(n=1865)$

\begin{tabular}{|c|c|c|c|c|}
\hline \multirow[b]{2}{*}{ Independent variables } & \multicolumn{2}{|c|}{ Systolic blood pressure } & \multicolumn{2}{|c|}{ Diastolic blood pressure } \\
\hline & $\beta(95 \% \mathrm{CI})$ & $P$ value & $\beta(95 \% \mathrm{Cl})$ & $P$ value \\
\hline $\begin{array}{l}\text { Apnoea-hypopnoea index } \\
\text { (1 apnoeic event) }\end{array}$ & $0.10(0.07-0.13)$ & 0.0001 & $0.07(0.05-0.09)$ & 0.0001 \\
\hline Age (1 year) & $0.39(0.34-0.44)$ & 0.0001 & $0.21(0.17-0.24)$ & 0.0001 \\
\hline Sex (male) & $-0.70(-2.50-1.11)$ & 0.45 & $2.05(0.86-3.24)$ & 0.0007 \\
\hline Neck circumference $(1 \mathrm{~cm})$ & $1.01(0.80-1.21)$ & 0.0001 & $0.47(0.33-0.61)$ & 0.0001 \\
\hline
\end{tabular}

multiple regression models cannot completely remove confounding effects, we confirmed our results by matching patients with sleep apnoea (apnoeahypopnoea index greater than 10 ; no use of antihypertensives), for age (within SD 5 years) and body mass

Table 4 Odds ratios for apnoea-hypopnoea index, body mass index, sex, age, and hypertension

\begin{tabular}{lcc} 
Variable & Estimate (Wald 95\% Cl) & Odds ratio \\
\hline Intercept & $-6.949(-7.686$ to -6.211$)$ & - \\
\hline Age (10 years) & $0.805(0.718$ to 0.892$)$ & 2.24 \\
\hline Sex (male) & $0.161(-0.061$ to 0.383$)$ & 1.17 \\
\hline Body mass index $\left(5 \mathrm{~kg} / \mathrm{m}^{2}\right)$ & $0.332(0.256$ to 0.409$)$ & 1.39 \\
\hline $\begin{array}{l}\text { Apnoea-hypopnoea index } \\
(10 \text { apnoeic events) }\end{array}$ & $0.116(0.075$ to 0.156$)$ & 1.12 \\
\hline
\end{tabular}

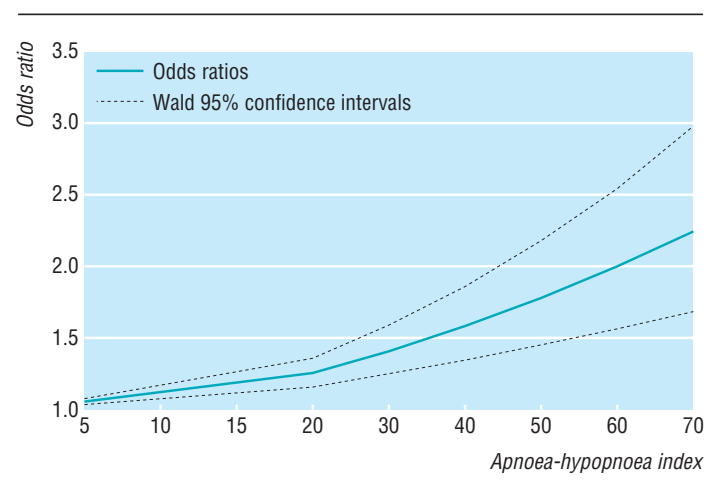

Fig 1 Odds ratios and Wald 95\% confidence intervals for hypertension associated with apnoea-hypopnoea index level of 5,15 , $30,40,50,60$, and 70 predicted by best fitting multiple logistic model: $T=e^{.012 a p n o e a-h y p o p n o e a ~ i n d e x .081 a g e ~}+.161$ male $+.067 \mathrm{body}$ mass index $(n=2452)$ 
Table 5 Odds ratios for nadir in nocturnal oxygenation, body mass index, sex, age, and hypertension

\begin{tabular}{lcc} 
Variable & Estimate (Wald 95\% Cl) & Odds ratio \\
\hline Intercept & $-5.890(-7.020$ to -4.761$)$ & - \\
\hline Age $(10$ years $)$ & $0.810(0.723$ to 0.896$)$ & 2.25 \\
\hline Sex (male) & $0.264(0.047$ to 0.482$)$ & 1.30 \\
\hline Body mass index $\left(5 \mathrm{~kg} / \mathrm{m}^{2}\right)$ & $0.360(0.282$ to 0.438$)$ & 1.43 \\
\hline Nadir $(10 \%$ decrease $)$ & $0.133(0.055$ to 0.212$)$ & 1.14 \\
\hline
\end{tabular}

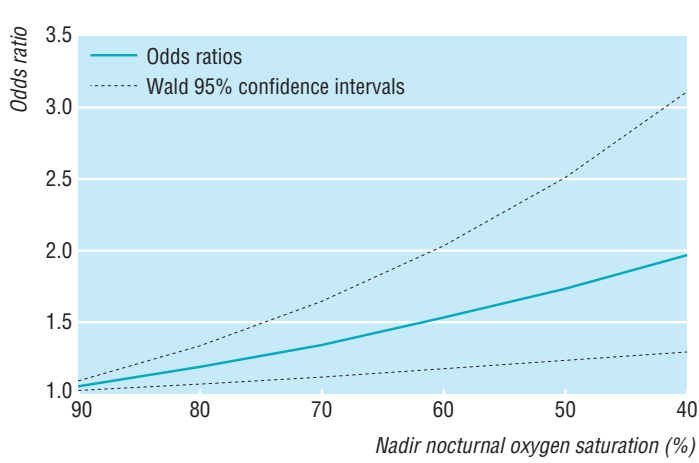

Fig 2 Odds ratios and Wald 95\% confidence intervals for hypertension associated with oxygen saturation nadir levels of $90 \%$, $80 \%, 70 \%, 60 \%, 50 \%$, and $40 \%$ predicted by model hypertension $=e^{-0133 n a d i r}+.081$ age +.265 male +.072 body mass index $(n=2451)$

index (within SD $2 \mathrm{~kg} / \mathrm{m}^{2}$ ) with controls (apnoeahypopnoea index 10 or less). The 674 patients with sleep apnoea we successfully matched (data not shown) had significantly higher blood pressure measurements than their matched controls (122.4 (SD 15.7) versus 118.7 (15.5) $\mathrm{mm} \mathrm{Hg}, \mathrm{t}=4.67$, paired $t$ test $\mathrm{P}<0.0001 ; 73.7$ (10.2) versus $70.9(9.9) \mathrm{mm} \mathrm{Hg}, \mathrm{t}=5.20, \mathrm{P}<0.0001)$.

Our $1 \%$ estimate of risk for hypertension for each event per hour of sleep is lower than the $4 \%$ previously reported. ${ }^{6}$ This may be because our reference group comprised a large number of heavy snorers who were suspected of having sleep apnoea but who were found to have an apnoea-hypopnoea index lower than 10 . Snoring was previously reported to be associated with increased levels of blood pressure.

\section{Active approach in diagnosis}

Our findings, together with previous reports, ${ }^{56}$ show that sleep apnoea constitutes an independent risk factor for hypertension. Multivariate analysis of mortality data in patients with sleep apnoea showed that hypertension was a significant independent predictor of cardiopulmonary deaths in these patients. ${ }^{10}$ These findings have clinical implications concerning diagnosis and treatment of sleep apnoea. Currently, most patients are referred for diagnosis only when symptoms are severe enough to affect their quality of life or to attract the attention of family members. Snorers, even with obvious daytime sleepiness, were reported to be passive in seeking medical help for their symptoms. ${ }^{11}$ The association of sleep apnoea with hypertension warrants a more active approach in the diagnosis of sleep apnoea.

We thank Ms Gay Natanzon for editing and checking the manuscript.

Contributors: PL designed the data analysis and wrote the paper. VH was responsible for data collection and organising the database and participated in writing the paper. $\mathrm{PH}$ performed the statistical analysis.
What is already known on this topic

Previous studies have suggested that sleep apnoea syndrome is associated with hypertension, but until now evidence from a large population attending a sleep clinic in which confounders were controlled for has been lacking

\section{What this paper adds}

Based on either medical history or actual blood pressure measurements there is an association between sleep apnoea and hypertension, which is independent of the most important confounders

Sleep apnoea syndrome should be taken into account in the differential diagnosis of essential hypertension

Funding: Technion Sleep Disorders Center (SDC).

Competing interests: None declared.

1 Hoffstein V, Chan CK, Slutsky AS. Sleep apnea and systemic hypertension: a causal association review. Am J Med 1991;91:190-6.

2 Fletcher EC. The relationship between systemic hypertension and obstructive sleep apnea: facts and theories. Am J Med 1995;98:118-28

3 Millman RP, Redline S, Carlisle CC, Assaf AR, Levinson PD. Daytime hypertension in obstructive sleep apnea. Prevalence and contributing risk factors. Chest 1991;99:861-86.

4 Silverberg DR, Oksenberg A, Radwan H, Iaina A. Sleep related breathing disorders are common distributing factors to the production of essential hypertension but are neglected, underdiagnosed and undertreated. $\mathrm{Am} \mathrm{J}$ Hypertens 1997;10:1319-25.

5 Hla KM, Young TB, Bidwell T, Palta M, Skatrud JB, Dempsey J. Sleep apnea and hypertension. A population-based study. Ann Intern Med 1994;120:382-8

6 Young T, Peppard P, Palta M, Hla KM, Finn L, Morgan B, Skatrud J. Population-based study of sleep-disordered breathing as a risk factor for hypertension. Arch Intern Med 1997;157:1746-52.

7 Wright J, Johns R, Watt I, Melville A, Sheldon T. Health effects of obstructive sleep apnoea and the effectiveness of continuous positive airways pressure: a systematic review of the research evidence. BMJ 1997;314:851-60.

8 Fleiss L. Statistical methods for rates and proportions, 2nd ed. New York: Wiley, 1981.

9 Young T, Finn L, Hla KM, Morgan B, Palta M. Snoring as part of a doseresponse relationship between sleep-disordered breathing and blood pressure. Sleep 1996;19:202-5S

10 Lavie P, Herer P, Peled R, Berger I, Yoffe N, Zomer J, et al. Mortality in sleep apnea patients-a multivariate analysis of risk factors. Sleep $1995 ; 18: 149-57$.

11 Martikainen K, Pertinen M, Urponen H, Vuori I, Laippala P, Hasa J. Natural evolution of snoring: a 5-year follow-up study. Acta Neurol Scand 1994;90:437-42.

(Accepted 2 December 1999)

\section{Notice of inadvertent duplicate publication}

The $B M J$ regrets that the paper "Screening for carcinoma of the prostate by digital rectal examination in a randomly selected population" by K V Pedersen, P Carlsson, E Varenhorst, O Lofman, and K Berglund (BMJ 1990;300:1041-4) was substantially similar to a paper published in Acta Oncologica (1991;30:273-5) entitled "Screening for carcinoma of the prostate in a randomly selected population using duplicate digital rectal examination" by E Varenhorst, K V Pedersen, P Carlsson, K Berglund, and O Lofman and to one published in Recent Results in Cancer Research (1993;126: 25-30) entitled "Screening for carcinoma of the prostate in a randomly selected population" by E Varenhorst, K V Pedersen, P Carlsson, K Berglund, and O Lofman. The two later papers make no reference to any earlier paper, and the editor of Acta Oncologica was not told of the existence of the earlier paper, in contravention of both the BMJ's and Acta Oncologica's instructions to authors and of internationally agreed guidelines (we have been unable to contact the editor of Recent Results in Cancer Research). Professor Varenhorst has apologised. 